\title{
Myocardial contractility is preserved early but reduced late after ovariectomy in young female rats
}

Altemar S Paigel, Rogerio F Ribeiro Junior, Aurelia A Fernandes, Gabriel P Targueta, Dalton V Vassallo and Ivanita Stefanon*

\begin{abstract}
Background: Ovarian sex hormones (OSHs) are implicated in cardiovascular function. It has been shown that OSHs play an important role in the long term regulation of cardiac sarcoplasmic reticulum (SR) function and contractility, although early effects of OSHs deprivation on myocardial contractility have not yet been determined. This study evaluated the early and late effects of OSHs deficiency on left ventricular contractility in rats after ovariectomy.

Methods: Young female Wistar rats were divided into 3 groups ( $n=9-15)$ : sham operated (Sham), ovariectomized $(\mathrm{Ovx})$ and $\mathrm{Ovx}$ treated with estradiol (1 mg/kg, i.m., once a week) (Ovx+E2). After 7, 15, 30 and 60 days post Ovx, left ventricle papillary muscle was mounted for isometric tension recordings. The inotropic response to $\mathrm{Ca} 2+(0.62$ to $3.75 \mathrm{mM}$ ) and isoproterenol (Iso 10-8 to 10-2 M) and contractility changes in response to rate changes (0.25 to 3 $\mathrm{Hz}$ ) were assessed. Protein expression of SR Ca2+-ATPase (SERCA2a) and phospholamban (PLB) in the heart was also examined.
\end{abstract}

Results: The positive inotropic response to $\mathrm{Ca} 2+$ and Iso at 7, 15, and 30 days after Ovx was preserved. However, at 60 days, the Ovx group had decreased myocardial contractility which was subsequently restored with E2 replacement. The reduction in SERCA2a and increase in PLB expression observed at 60 days after Ovx were restored with E2 replacement.

Conclusion: This study demonstrated that myocardial contractility and expression of key Ca2+ handling proteins were preserved in the early phase and reduced at long-term during OSHs deprivation.

\section{Background}

Cardiovascular disease is a major contributor to morbidity and mortality among post-menopausal women in the western world [1]. Interestingly, pre-menopausal women have a reduced risk of mortality from cardiovascular disease while post-menopausal women have a similar or even increased risk for cardiovascular disease as compared to men [2]. It has been suggested that ovarian sex hormones (OSHs) have a protective effect on the cardiovascular system $[2,3]$. However, the effects of estrogen replacement therapy on the cardiovascular risk only account for about $50 \%$ of the reduction seen in cardiovascular disease suggesting that there must be additional

\footnotetext{
* Correspondence: ivanita@pq.cnpq.br
Federal University of Espirito Santo, Department of Physiological Sciences,

* Correspondence: ivanita@pq.cnpq.br
Federal University of Espirito Santo, Department of Physiological Sciences, Vitória, ES, Brazil
}

(c) 2011 Paigel et al; licensee BioMed Central Ltd. This is an Open Access article distributed under the terms of the Creative Commons

mechanisms whereby estrogen exerts its cardioprotective effects [4]. Though observational and experimental studies have suggested that ovarian sex hormones (OSHs) replacement therapy may be cardioprotective [5,6], large trials utilizing oral conjugated estrogen and medroxyprogesterone acetate did not confirm these findings [7].

In the last few years, the main ovarian hormone, estrogen (E2), has received special attention for its protective effects against atherosclerosis [8,9]. Several studies have also indicated that E2 directly protective of cardiac muscle contractility $[10,11]$. However, though studies have indicated that OSHs therapy restore contractile performance in post-menopausal women [12-14], short-term of cardiac effects of ovariectomy and E2 replacement have not been demonstrated. 
Recent studies further suggest that mechanical functioning and proteomic profiles in ventricular myocytes are directly regulated by E2 [15-18]. However, those studies only investigated cardiac performance and proteins involved in $\mathrm{Ca}^{2+}$ homeostasis at 4 to 10 weeks after OSHs deprivation leaving short-term effects of OSHs deprivation on myocardial contractility poorly understood. Thus, our aim was to study the inotropic response of left ventricular papillary muscles short and long-term (7, 15, 30 and 60 days) after ovariectomy in young female rats. We also investigated the expression of cardiac regulatory proteins sarcoplasmic reticulum (SR) $\mathrm{Ca}^{2+}$-ATPase (SERCA2a), phospholamban (PLB) and sodium-calcium exchanger (NCX) at 7, 15, 30 and 60 days after Ovx. We studied the expression of these proteins primarily due the fact that PLB regulates the $\mathrm{Ca}^{2+}$-affinity of SERCA2a, facilitating calcium uptake into the SR and muscle relaxation, which is considered an important intracellular mechanism involved in myocardial contractility $[19,20]$.

\section{Methods}

\section{Animal care}

The care and use of the laboratory animals were in accordance with National Institutes of Health (NIH) guidelines and were approved by the local animal ethics committee. All rats had free access to water and were fed with food ad libitum.

Experimental groups, surgical procedures and E2 replacement. Eight-week-old female Wistar rats weighting $185 \mathrm{~g}$ approximately were randomly divided into two groups. One group underwent bilateral ovariectomy (Ovx) as described previously [21]. Briefly, a dorsal midline skin incision was made under anesthesia caudal to the posterior border of the ribs. The posterior abdominal muscle wall was bluntly dissected, the abdominal cavity was opened and the ovary was gently exteriorized and removed. The uterine horn was returned into the abdomen. The skin incision was closed with sterile nylon sutures, and the process was repeated on the other side. At 1 week after Ovx, a subgroup of the ovariectomized rats $(\mathrm{Ovx}+\mathrm{E} 2)$ started treatment with estradiol valerate (E2) $1 \mathrm{mg} / \mathrm{Kg}$ injected, i.m., once a week for 8 weeks. The second group underwent a sham operation and served as normal controls (sham). Left ventricle papillary muscle contractility was studied at 7 , 15, 30 and 60 days after surgery. E2 replacement was carried out only in the 60 day ovariectomized subgroup because it was the only group that showed a reduction in myocardial contractility. At the time of sacrifice, adequacy of the ovariectomy was determined grossly by the absence of ovarian tissue and marked atrophy of the uterus [16]. We also determined the weight of the entire animal, as well as the weight of the left and right ventricles and the uterus.

\section{Isometric tension and myocardial contractility}

Rats received 500 units of heparin intraperitoneal (i.p.) and then were anesthetized 10 minutes later with 45 $\mathrm{mg} / \mathrm{kg}$ sodium pentobarbital, i.p., (Cristália, SP, Brazil). Hearts were rapidly removed and perfused through the aortic stump and the left ventricle papillary muscles were dissected. Muscle preparations were mounted for isometric tension recording and maintained in a $20 \mathrm{~mL}$ glass-bath containing Krebs-Henseleit solution (in mM: $\mathrm{NaCl} 118, \mathrm{KCl} 4.7, \mathrm{CaCl}_{2} 1.25, \mathrm{KH}_{2} \mathrm{PO}_{4} 1.2, \mathrm{MgSO}_{4}$ 1.2, $\mathrm{NaHCO}_{3} 23$ and glucose 11 ) at $30^{\circ} \mathrm{C}$ and $\mathrm{pH}=7.4$, which was continuously aerated with $95 \% \mathrm{O}_{2}$ and $5 \%$ $\mathrm{CO}_{2}$. Resting tension was adjusted to produce maximal contractile force (Lmax). The twitch contraction rate was controlled by isolated rectangular pulses (10 to 15 $\mathrm{V}, 12 \mathrm{~ms}$ duration) through a pair of platinum electrodes. The standard stimulation rate was $0.5 \mathrm{~Hz}$ (steadystate). Isometric force development was measured with an isometric force transducer (TSD105A, Biopac) and normalized to muscle weight $(\mathrm{g} / \mathrm{g})$. Recording started after 60 minutes to permit the muscle to adapt to the new environmental conditions. Myocardial contractility was tested by the following protocol. First, we measured the inotropic response to changes in extracellular calcium concentration $\left(\mathrm{Ca}^{2+}, 0.62\right.$ to $\left.3.75 \mathrm{mM}\right)$. Next, the positive inotropic response, produced by increasing isoproterenol concentrations added to the bath $\left(10^{-8}-10^{-2}\right.$ $\mathrm{M})$, was analyzed. Finally, we evaluated the isometric force development relationship at stimulation rates of 0.25 to $3.0 \mathrm{~Hz}$. At the end of the experiment, the papillary muscle was removed and weighed for force normalization $(\mathrm{g} / \mathrm{g})$.

\section{Serum estrogen level}

Blood samples were collected in tubes with anticoagulant from group at 60 days after surgery. Blood samples were centrifuged at $1,500 \mathrm{~g}$ for $15 \mathrm{~min}$ at $4^{\circ} \mathrm{C}$. The resulting serum was kept at $-80^{\circ} \mathrm{C}$ until used to determine estrogen levels. The $\mathrm{E}_{2}$ levels in the serum were measured using ELISA technique according to the manufacturer's instruction.

\section{Western blot analysis of SERCA2a, NCX and PLB}

Proteins from homogenized hearts $(100 \mu \mathrm{g})$ were separated by $7.5 \%$ (SERCA2a and NCX) or 15\% (PLB) SDSPAGE. Proteins were transferred to nitrocellulose membranes for SERCA2a and NCX and polyvinyl difluoride membranes for PLB and were incubated with mouse monoclonal antibodies for SERCA2a (1:1000, Affinity BioReagents, CO, USA), NCX (1:200, Abcam 
Cambridge, MA, USA) and PLB ( $1 \mu \mathrm{g} / \mathrm{ml}$, Affinity BioReagents, CO, USA). After washing, membranes were incubated with anti-mouse (1:5000, StressGen, Victoria, Canada) immunoglobulin antibody conjugated to horseradish peroxidase. After thorough washing, immunocomplexes were detected using an enhanced horseradish peroxidase/luminal chemiluminescence system (ECL Plus, Amersham International, Little Chalfont, UK) and film (Hyperfilm ECL International). Signals on the immunoblot were quantified with the National Institutes of Health Image V1.56 computer program. The same membrane was used to determine GAPDH expression using a mouse monoclonal antibody (1:5000, Abcam Cambridge, MA, USA).

\section{Statistical analysis}

All values are expressed as mean \pm SEM. Differences among groups were analyzed using the two way ANOVA test followed by the Tukey post hoc test for multiple comparisons. A p value $<0.05$ was considered statistically significant. For protein expression, data are expressed as the ratio between protein and GAPDH signals.

\section{Drugs and chemicals}

All chemicals, unless specified in the text, were purchased from Sigma Chemical (St. Louis, MO).

\section{Results}

\section{Rat weights}

The body weights of the ovariectomized rats were significantly greater than those of sham controls at 15, 30 and 60 days (Table 1). E2 treatment prevented weight gain at 60 days after ovariectomy and also restored the estrogen levels at the same levels as the control animals (Sham: $127 \pm 11.5 \mathrm{pmol} / \mathrm{L}$, Ovx : $50.4 \pm 11.4^{*} \mathrm{pmol} / \mathrm{L}$ and $\mathrm{Ovx}$ + E2: $142.2 \pm 31 \mathrm{pmol} / \mathrm{L} ; \mathrm{p}<0.05)$. Ovariectomy and E2 replacement did not alter the left or right ventricle weight to body weight ratio. Starting at 7 days, the deficiency of OSH induced a significant decrease in uterine weight compared with that of sham controls.
Restoration of uterine mass was observed in the E2 treated group (Table 1).

\section{Isometric contractility response to calcium}

It is well known increases in extracellular $\mathrm{Ca}^{2+}$ results in enhanced calcium influx through L-type $\mathrm{Ca}^{2+}$ channels triggering further $\mathrm{Ca}^{2+}$ release from $\mathrm{Ca}^{2+}$ stores within the SR [22]. This in turn leads to a rise of intracellular free $\mathrm{Ca}^{2+}$ culminating in myofilament shortening and cell contraction. As expected, increases in extracellular $\mathrm{Ca}^{2+}$ resulted in a positive inotropic response (Figure 1). We found no significant differences in the inotropic response to calcium at 7,15 , and 30 days among ovariectomy and control groups. However, deprivation of OSHs at 60 days induced a reduction in the inotropic response to extracellular $\mathrm{Ca}^{2+}$.

Force increases with increasing myocardial mass, characterizing a positive correlation between theses variables. Assuming the 60 days group is older and the papillary muscles are heavier, we expected to find higher values for all parameter in the 60 days groups. As the OVX group has a contractility dysfunction, the force did not increase as expected.

\section{Isometric contractile response to $\beta$-adrenergic receptor stimulation}

Using a nonspecific $\beta$-adrenergic agonist, isoproterenol, dose-response curves were assessed (Figure 2). Stimulation of this subtype of $\beta$-adrenergic receptor in the heart by isoproterenol increases contractility and accelerates relaxation by activating the adenylyl cyclase/cAMP/protein kinase pathway [23]. As expected, isoproterenol promoted a positive inotropic effect in all groups examined. However, the positive inotropic response was decreased in the ovariectomized group at 60 days compared with sham controls.

\section{Force-frequency relationship}

The relationship between rate and isometric force (Figure 3) is species-specific and was first described by Bowditch in 1871. In the rat, a reverse staircase phenomenon has been demonstrated, where force of

Table 1 Weight data from sham, ovariectomized (Ovx) and estrogen replacement

\begin{tabular}{|c|c|c|c|c|c|c|c|c|c|}
\hline & \multicolumn{2}{|c|}{7 days } & \multicolumn{2}{|c|}{15 days } & \multicolumn{2}{|c|}{30 days } & \multicolumn{3}{|c|}{60 days } \\
\hline & Sham & Ovx & Sham & Ovx & Sham & Ovx & Sham & Ovx & $\mathrm{Ovx}+\mathrm{E} 2$ \\
\hline BW (g) & $195 \pm 3$ & $201 \pm 5$ & $204 \pm 3$ & $232 \pm 8^{*}$ & $233 \pm 3$ & $274 \pm 5^{*}$ & $256 \pm 5$ & $310 \pm 9^{*}$ & $251 \pm 9^{\#}$ \\
\hline LV/BW (mg/g) & $2.25 \pm 0.06$ & $2.12 \pm 0.07$ & $2.21 \pm 0.07$ & $2.07 \pm 0.05$ & $2.25 \pm 0.09$ & $2.09 \pm 0.06$ & $2.0 \pm 0.03$ & $1.9 \pm 0.04$ & $1.93 \pm 0.05$ \\
\hline $\mathrm{RV} / \mathrm{BW}(\mathrm{mg} / \mathrm{g})$ & $0.57 \pm 0.02$ & $0.55 \pm 0.02$ & $0.52 \pm 0.02$ & $0.53 \pm 0.01$ & $0.54 \pm 0.01$ & $0.58 \pm 0.04$ & $0.48 \pm 0.03$ & $0.49 \pm 0.02$ & $0.54 \pm 0.02$ \\
\hline Uterus/BW (mg/g) & $2.09 \pm 0.14$ & $0.70 \pm 0.04^{*}$ & $2.40 \pm 0.17$ & $0.60 \pm 0.05^{*}$ & $1.96 \pm 0.07$ & $0.47 \pm 0.04^{*}$ & $2.60 \pm 0.16$ & $0.45 \pm 0.04^{*}$ & $2.56 \pm 0.19^{\#}$ \\
\hline Papillary Muscle (mg) & $5.5 \pm 0.46$ & $5.6 \pm 0.56$ & $4.9 \pm 0.35$ & $6.1 \pm 0.51$ & $4.11 \pm 0.36$ & $5.0 \pm 0.4$ & $5.2 \pm 0.47$ & $5.7 \pm 0.33$ & $5.9 \pm 0.5$ \\
\hline
\end{tabular}

LV - Left Ventricle, RV - Right Ventricle, BW - Body Weight. Data are expressed as mean \pm SEM.

${ }^{*} \mathrm{OV} x$ vs Sham, ${ }^{\#}$ Ovx $+\mathrm{E} 2$ vs Ovx, $\mathrm{p}<0.05$ unpaired t-test. $\mathrm{N}=6-15(\mathrm{Ovx}+\mathrm{E} 2)$ groups 

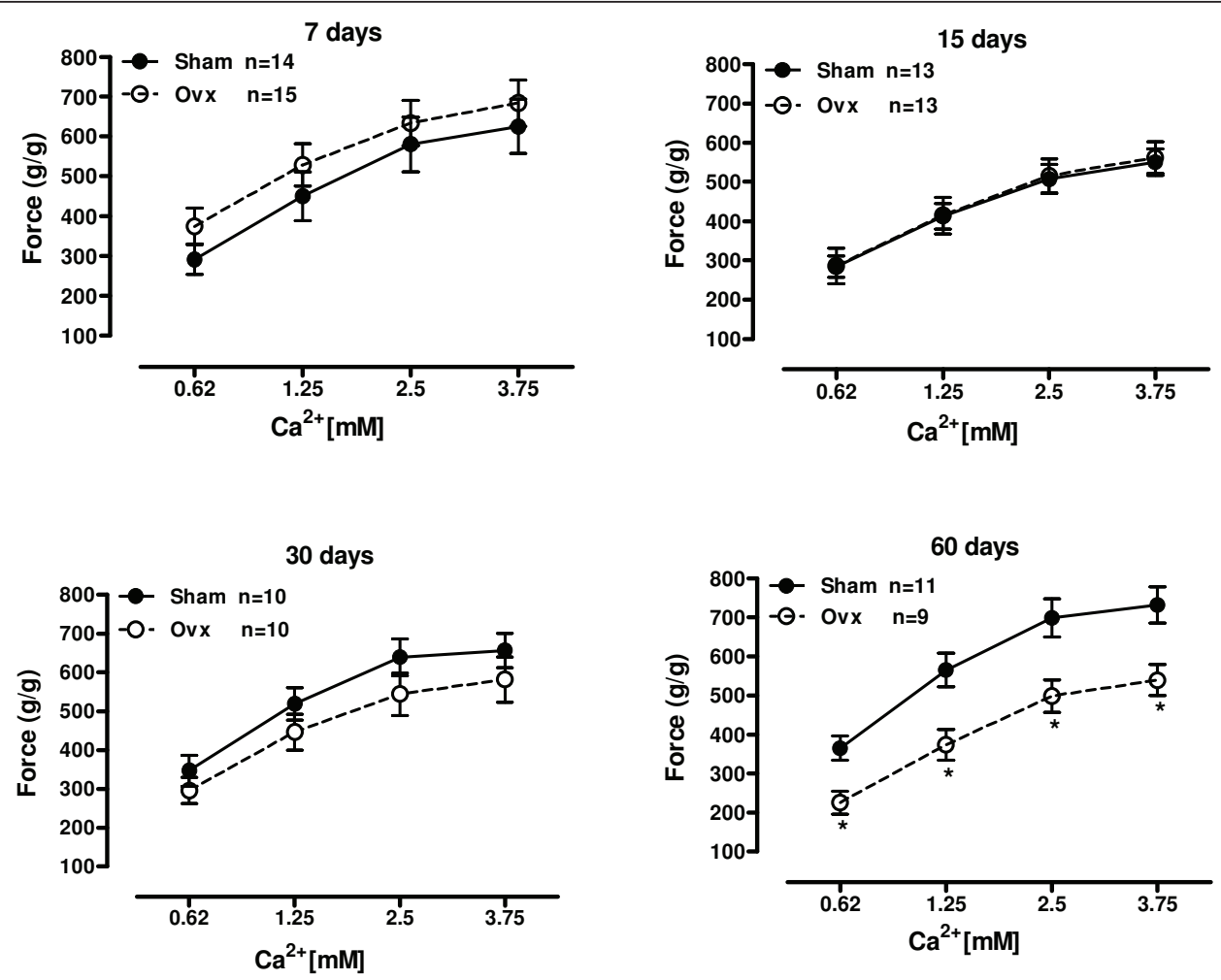

Figure 1 Inotropic response to calcium. Effect of increasing extracellular calcium concentration from 0.62 to $3.75 \mathrm{mM}$ on force development in isolated left ventricle papillary muscles from sham operation (Sham) and ovariectomized (Ovx) rats at 7, 15, 30 and 60 days after surgery. Force $(\mathrm{g} / \mathrm{g})$ values are expressed as mean \pm S.E.M. ${ }^{*}$ different from sham $(P<0.05)$ using two-way ANOVA and post hoc Tukey test. Number of animals used is indicated.
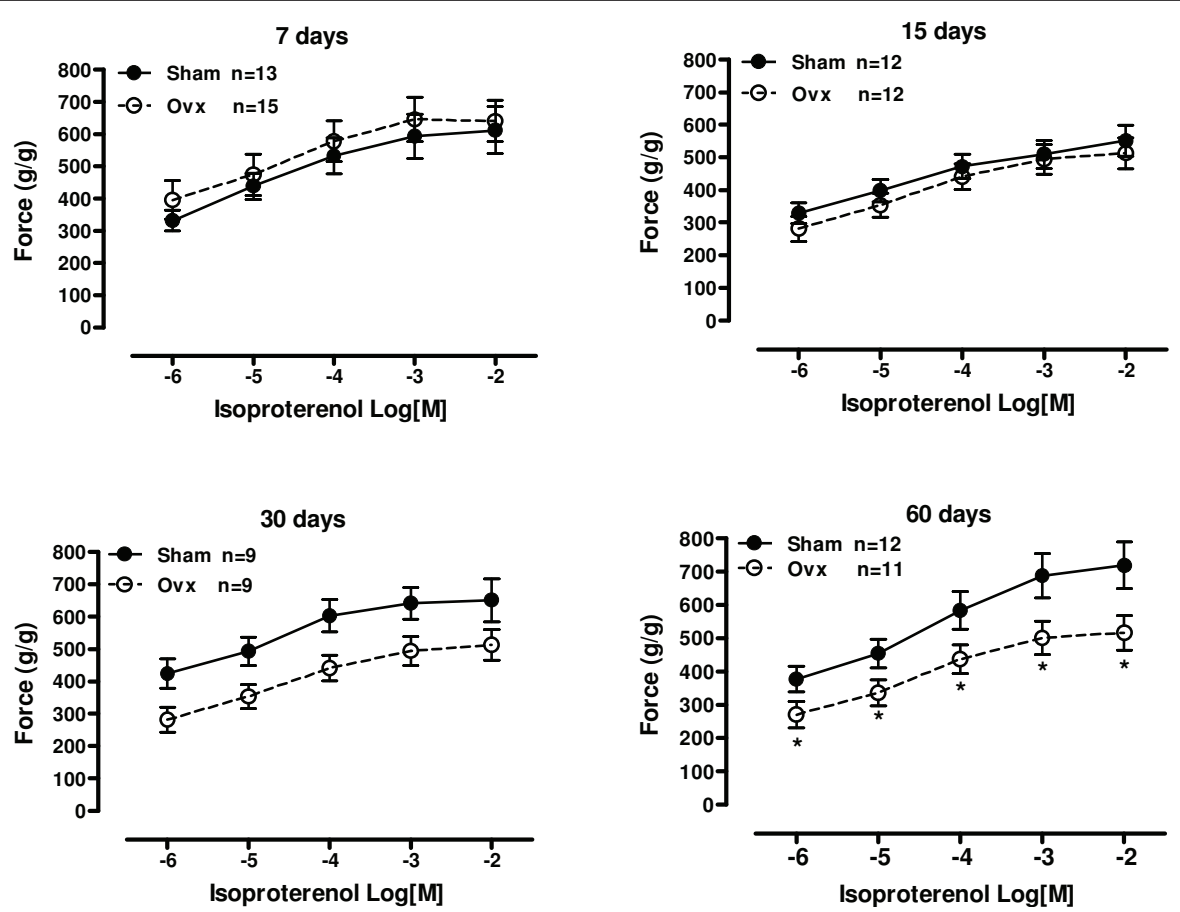

Figure 2 Inotropic response to isoproterenol. Effect of the $\beta$-adrenergic agonist isoproterenol in increasing concentrations from $10^{-8}$ to $10^{-2}$ $\mathrm{M}$ on force development in isolated left ventricle papillary muscles from Sham operation (Sham) and ovariectomized (Ovx) rats at 7, 15, 30 and 60 days after surgery. Extracellular $\mathrm{Ca}^{2+}$ concentration was $0.62 \mathrm{mM}$. Force $(\mathrm{g} / \mathrm{g})$ values are expressed as mean \pm S.E.M. ${ }^{*}$ different from sham $(P<$ 0.05) using two-way ANOVA and post hoc Tukey test. Number of animals used is indicated. 


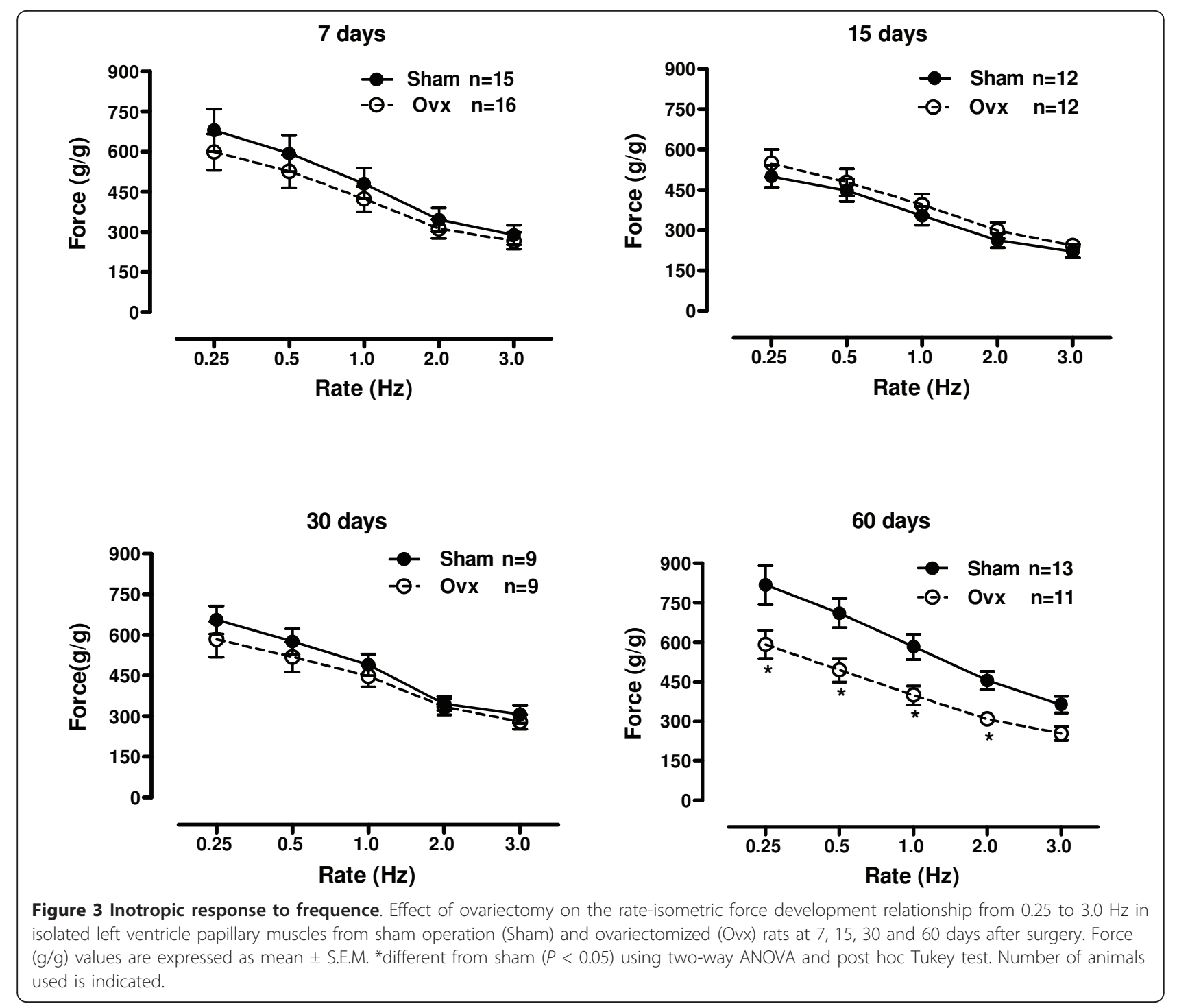

contraction falls as heart rate increases. It has been demonstrated that the time to peak isometric force varies directly with the duration of the active state, and thus changes in duration are reflected in changes in the peak force [24]. The Bowditch staircase phenomenon was investigated by changing the stimulation rate from 0.25 to $3.0 \mathrm{~Hz}$ following rest periods of approximately $60 \mathrm{~s}$. As expected, a decrease in rate of stimulation produced an immediate increase in peak force. This inverse relationship was preserved in all groups, and was similar between controls and Ovx rats at 7, 15 and 30 days but reduced in Ovx rats at 60 days.

Effect of ovariectomy on maximum positive and negative force derivatives

To determine whether the contractile deficit found in the inotropic response to calcium and isoproterenol was also observed in the activation or relaxation phase of force development, we measured the positive and negative rate of force development $(\mathrm{dF} / \mathrm{dt}$ ) (Figure 4). Positive $\mathrm{dF} / \mathrm{dt}$ was reduced at 60 days after Ovx in all inotropic interventions assayed. There were no significant differences in negative $\mathrm{dF} / \mathrm{dt}$ between Ovx and sham groups.

\section{Estrogen replacement therapy}

As previously stated, ovariectomy-induced deficiency in OSH resulted in a significant decrease in inotropic response only after long-term (60 days) hormone deprivation. To determine if estrogen was involved in this effect, ovariectomized rats were treated with estradiol valerate for 8 weeks starting one week after surgery. Estrogen replacement efficiently prevented the decrease in the positive inotropic response to extracellular $\mathrm{Ca}^{2+}$ 


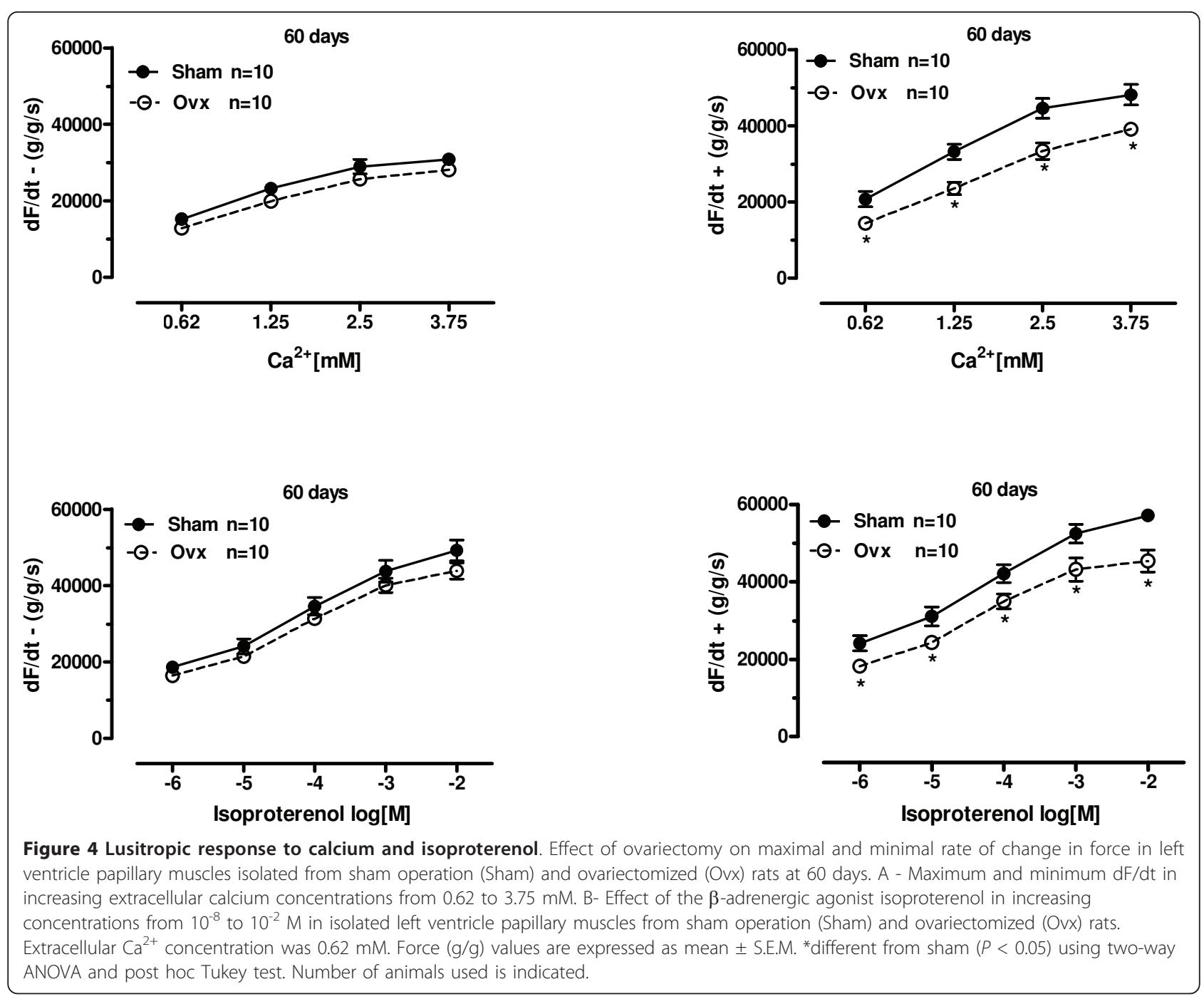

(Figure 5A) and isoproterenol (Figure 5B), and also restored the force-frequency relationship (Figure 5C).

\section{Western blot analysis of SERCA2a, NCX and PLB}

Alterations to cardiac mechanical properties and intracellular calcium homeostasis are dependent on SERCA2a, PLB and NCX. In this study, we examined the role of these proteins in the altered myocardial contractility seen in rats 60 days after ovariectomy. As shown in the Figure 6A and 6B, Ovx altered SERCA2a. Ovx reduced SERCA2a protein expression and increased PLB protein expression in the heart. E2 administration was effective in preventing those changes. Figure $6 \mathrm{C}$ demonstrates that PLB was overexpressed by 1.6 fold compared to the sham group. Meanwhile, NCX protein expression remained unchanged (Figure 6D). We also evaluated SERCA2a and PLB in rats at 7, 15 and 30. SERCA2a and PLB did not differ between Sham and Ovx at 7, 15 and 30 days after ovariectomy (Figure 7)

\section{Discussion}

This study examines the effects of OSHs deprivation on cardiac contractility in rats at both short and late-term periods after ovariectomy. Our results demonstrated myocardial contractility was preserved short-term. However, at long-term, deficiency in OSHs reduced cardiac contractility which was associated with changes in expression of key contractile proteins, SERCA2a and PLB. The long-term ovariectomy-induced reduction in myocardial contractility corroborates data previously described [15-18]. The novel finding in this study is that changes in contractility due to ovariectomy were not evident until 60 days after hormone loss. Interestingly, myocardial contractility, analyzed at 7, 15 and 30 days, was preserved during basal conditions and even under positive inotropic stimuli. Besides, at 60 days the Sham group showed an increasing in myocardial contractility response to calcium and Isoproterenol corroborating data previously described [26]. 

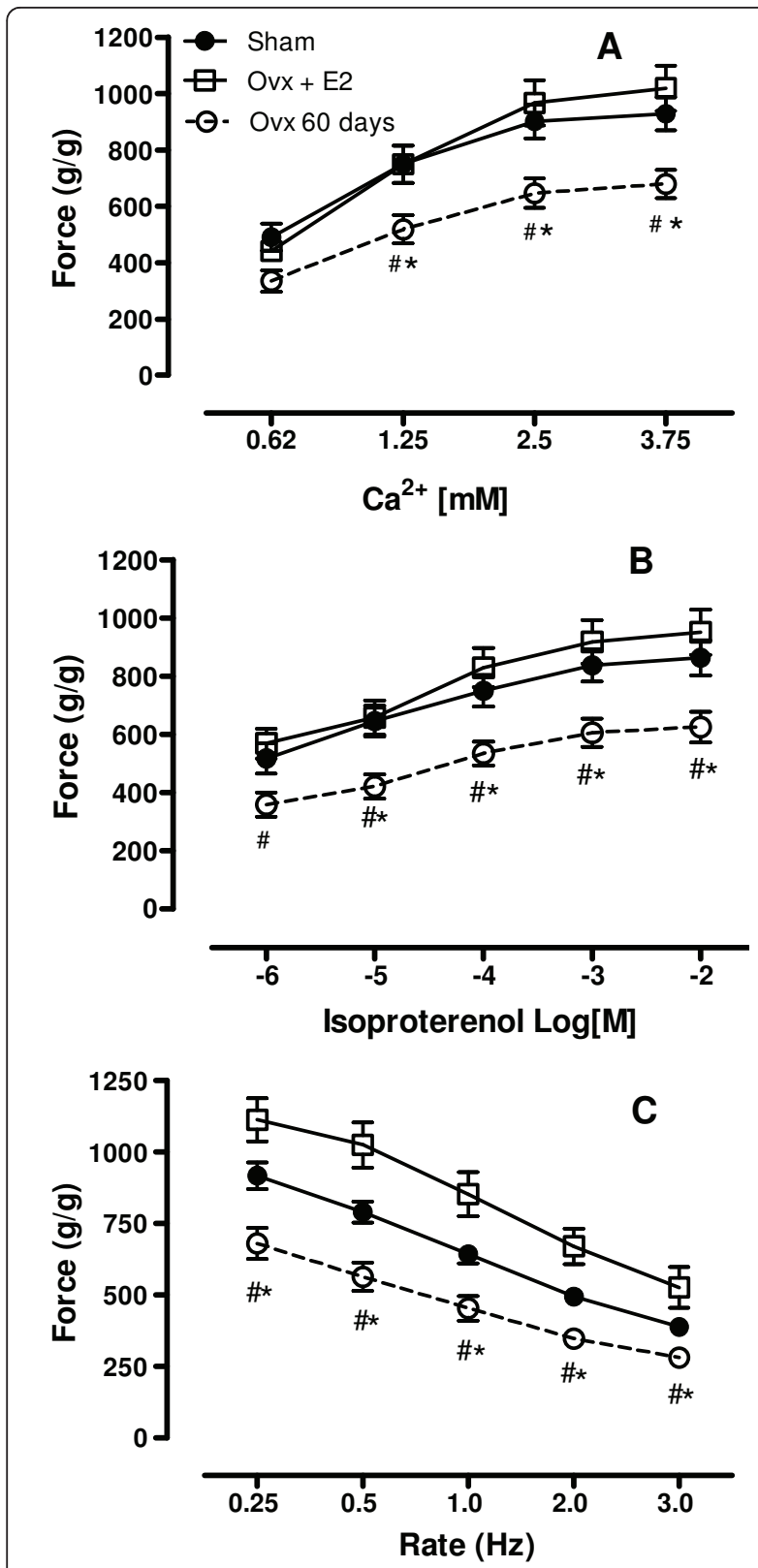

Figure 5 Estrogen effects on inotropic stimulus. Effect of estrogen replacement therapy with estradiol valerate on myocardial contractility 60 days after ovariectomy. Estrogen restores inotropic response to extracellular calcium (A) and isoproterenol (B) as well as the rate-isometric force development relationship (C). Force $(\mathrm{g} / \mathrm{g})$ values are expressed as mean \pm S.E.M. ${ }^{*}$ Ovx $n=8$ vs. Sham $n=22$, \# Ovx vs. Ovx + E2 $n=8$, different $(P<0.05)$ using two-way ANOVA and post hoc Tukey test.

Our results demonstrated that the PLB to SERCA2a ratio was increased at 60 days in the Ovx group by approximately 1.6 -fold and was normalized after E2 treatment. The protein expression of NCX remained unchanged. Based on transgenic and gene-targeted mouse model studies, alterations to the PLB to
SERCA2a ratio has been suggested to be a major regulator of cardiac contractility [25,27]. In vivo studies using transgenic mice which overexpress cardiac specific PLB suggested that the "functional stoichiometry" of PLB/ SERCA2 is less than 1:1 in native cardiac sarcoplasmic reticulum membranes [27]. Two-fold higher PLB protein levels in these transgenic mice as compared to WT, resulted in greater inhibition of $\mathrm{Ca}^{2+}$-ATPase affinity for $\mathrm{Ca}^{2+}$, which was associated with decreases in contractility and $\mathrm{Ca}^{2+}$ transport in cardiomyocytes.

This suggests that changes observed in SR protein expression at 60 days in Ovx rats may be responsible for the reduced contractility observed. Further, because E2 replacement restored SR protein expression and myocardial contractility, it is plausible that OSHs participate in the long-term regulation of cardiac contractility. In fact, a previous study observed thyroid hormone regulation of SR protein expression and cardiac contractility [28]. These authors also observed enhanced cardiac PLB expression which was associated with decreased rates of cardiac SR $\mathrm{Ca}^{2+}$ uptake which is consistent with increased inhibition of the cardiac SR $\mathrm{Ca}^{2+}$ pump and decreased contractility in hypothyroid rats.

Long-term studies demonstrated the influence of OSHs on rat cardiac contractility [13] through impaired left ventricular function. Impaired function was characterized by decreases in cardiac output, peak systolic pressure and ejection fraction at all preloads in the hearts of rat ovariectomized before puberty. These contractile changes were further associated with a decrease in myosin ATPase activity. Another study [14] demonstrated the same changes in cardiac function which were reversed by E2 replacement. Further studies reporting changes in intracellular $\mathrm{Ca}^{2+}$ homeostasis in cardiomyocytes suggest a possible modulating effect of $\mathrm{OSH}$ deficiency on the $\mathrm{Ca}^{2+}$ responsiveness of cardiac myofilament activation by induction of myofilament $\mathrm{Ca}^{2+}$ hypersensitivity but suppression of maximum myofibrillar ATPase activity $[28,16]$, which may underlie the cardiac dysfunction observed in OSHs deficiency. These findings support our results. The regulatory role of OSHs in the calcium uptake activity of cardiac SR was also demonstrated in 10 week ovariectomized rat hearts [16]. These authors demonstrated that estrogen and progesterone supplementation were equally effective in preventing changes in ovariectomized hearts.

In our study, 30 days after Ovx, myocardial isometric contractility in response to extracellular $\mathrm{Ca}^{2+}$ and $\beta$ adrenergic agonist as well as the rate-force development relationship were preserved. In another study, hormone status did not affect levels of SERCA2a, PLB, ryanodine receptor and the mRNA encoding for $\beta_{1}$-adrenoreceptor at 4 weeks post ovariectomy in rat [17]. Chu et al. 
A
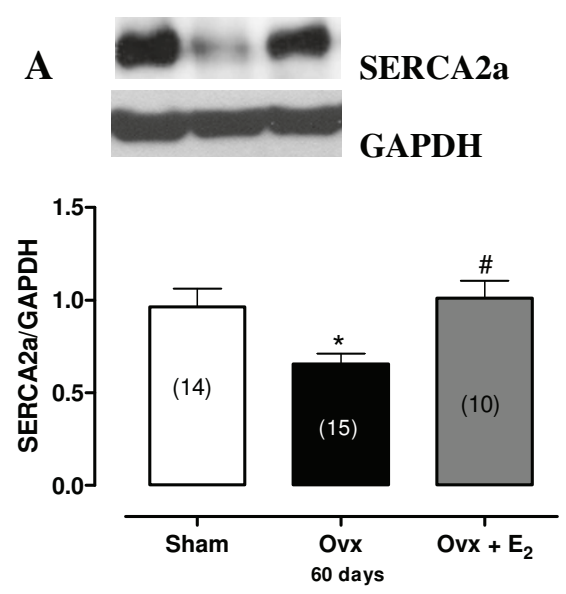

C

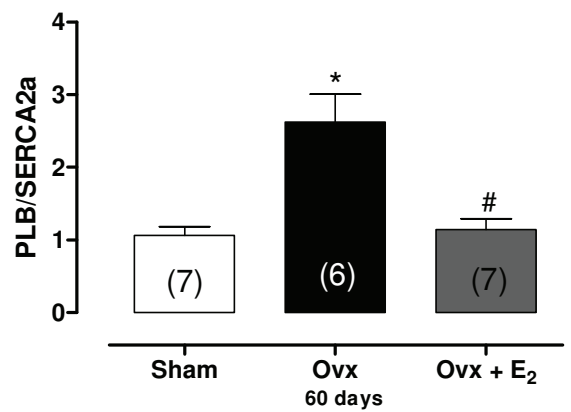

B
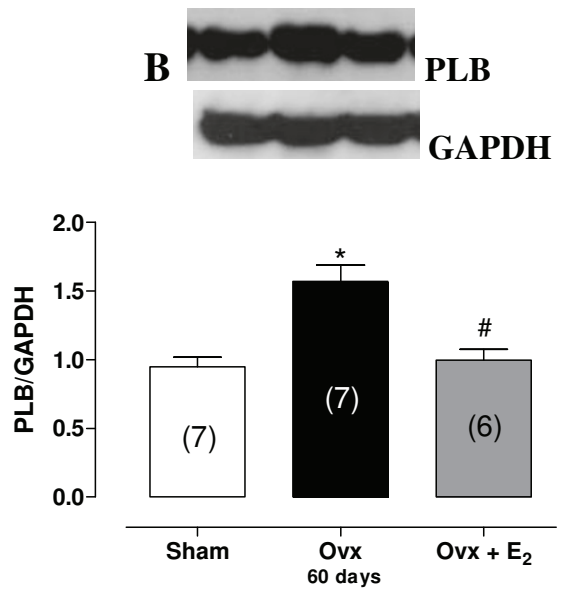

D
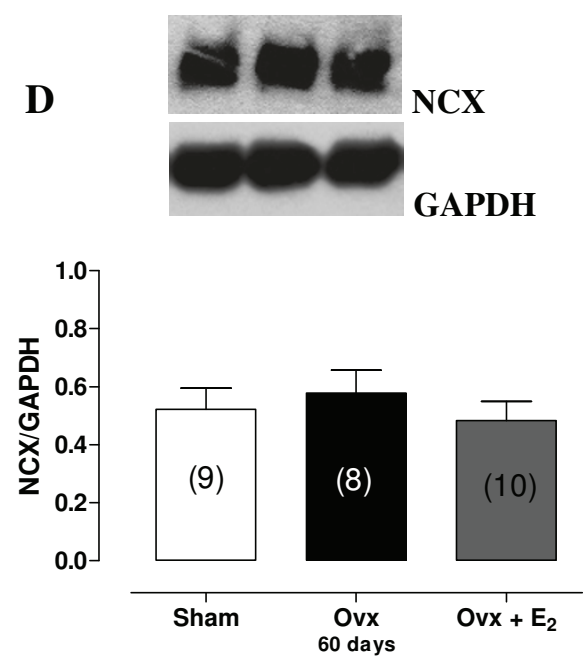

Figure 6 Calcium handling protein expression. Densitometric analysis of Western blots for (A) SR Ca ${ }^{2+}$-ATPase (SERCA2a), (B) phospholamban (PLB), (C) SERCA2a/PLB ratio and (D) sodium - calcium exchange (NCX) in hearts from sham, Ovx and Ovx $+E_{2}$ rats. * $p<0.05$ by ANOVA vs. Sham rats. \# $p<0.05$ by ANOVA vs. Ovx rats. Number of animals used is indicated in parentheses. Representative blots are shown.

further demonstrated that there was no difference in the isoproterenol-elicited increase in developed force though the abundance of $\beta_{1}$-adrenoreceptor was over 2 -fold higher in the Ovx group compared with Sham.

We also conducted our study at an early stage after ovariectomy. Rat hearts were studied at 7 and 15 days post ovariectomy. Clear evidence of $\mathrm{OSH}$ absence was observed as early as 7 days after ovariectomy with a close to 3-fold reduction in uterus weight compared to sham animals. In addition, there was an increase in body weight in the Ovx rats at 15 days. However, myocardial contractility was preserved in these animals.

E2 receptor signaling in the cardiovascular system is a complex process that is not completely understood. Its effects on the vascular system have been demonstrated in normal rats [30] and after myocardial infarction [31]. It is well recognized that E2 has genomic and non- genomic actions. The long-term effects of estrogen are mediated by different nuclear hormone receptors, ER $\alpha$ and ER $\beta$, which are encoded by different genes and act as ligand-dependent transcription factors [32]. To date, a number of mechanisms have been proposed to decipher the cardio protective effects of E2. E2 alters the expression of ventricular $\beta_{1}$-adrenoreceptor $[17,33]$, intracellular calcium homeostasis related to the L-type $\mathrm{Ca}^{2+}$ channel [35], cardiac SR $\mathrm{Ca}^{2+}$ uptake [16] and $\mathrm{Ca}^{2}$ ${ }^{+}$sensitivity of cardiac myofilaments in ovariectomized rats [29], which are important mediators of cardiac contractility. Although a cardiac transcriptional regulation of estrogen is well described, there is little direct evidence of membrane cardiac estrogen receptors. Data reporting on the non-genomic signal transduction in cardiomyocytes have demonstrated that $17 \beta$ estradiol has a negative inotropic effect on guinea-pig single 


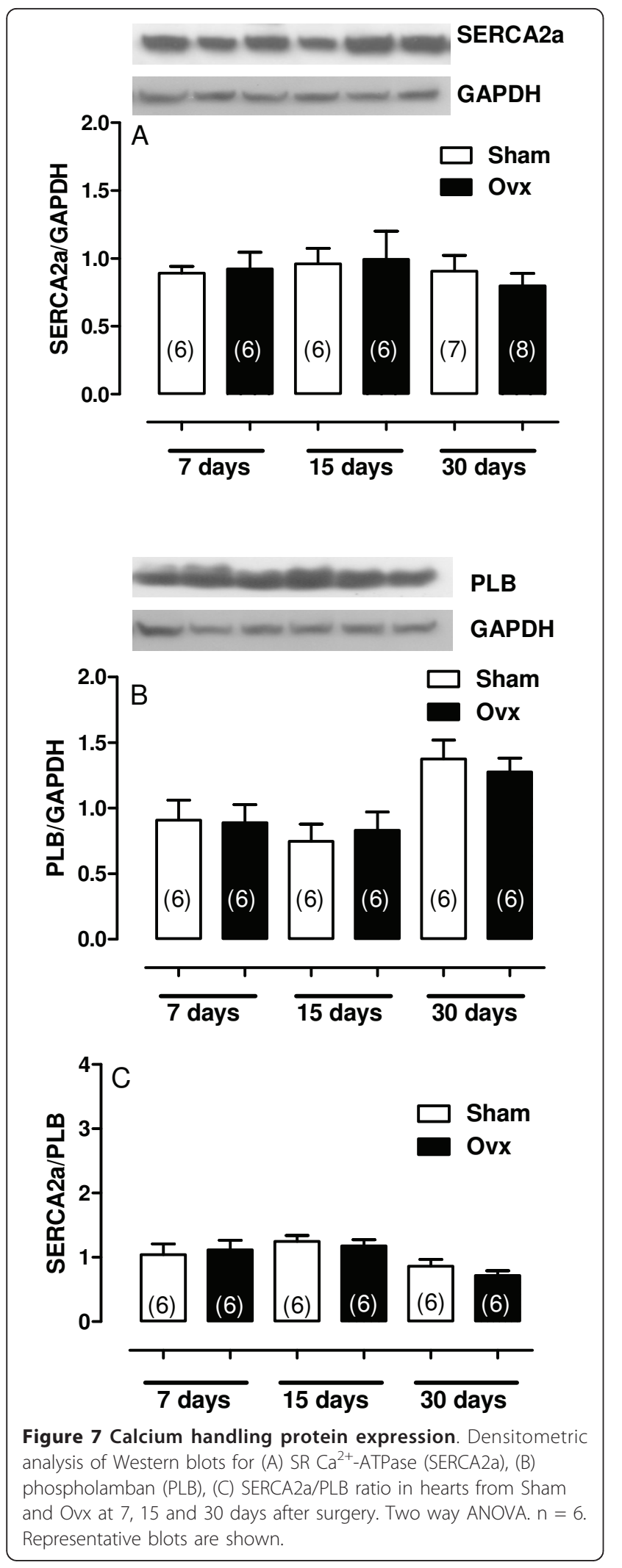

ventricular myocytes by inhibiting $\mathrm{ICa}$ and so reducing systolic $\mathrm{Ca}^{2+}[35]$.

Furthermore, in isolated rat ventricular cardiomyocytes, it was demonstrated that E2 exerts opposite effects on intracellular myocyte $\mathrm{pH}$, which is associated with pro-and anti-hypertrophic effects [36].

A question raised by the results presented here is whether OSHs affects the myocardium directly or by secondary mechanisms involving other hormones modulated by E2. Also, as contractility was altered so late after loss of OSHs, does E2 act only by genomic mechanisms, or are compensatory mechanisms involved in the short term? Further studies are necessary to clarify these questions. Taken together, our results suggest that changes in $\mathrm{Ca}^{2+}$ handling due to abnormal SR function may contribute to reduced myocardial contractility in chronically $\mathrm{OSH}$-deficient rats. Further studies would be beneficial to determine the importance of these findings in humans, as there are significant species-dependent differences in PLB regulation of SERCA2a [37]. Further, long-term rather than short-term estrogen suppression lead to contractile dysfunction which was subsequently reversed with estrogen replacement.

\section{Conclusions}

In conclusion, the most novel aspect demonstrated in this study is the long delay in development of cardiac dysfunction after ovariectomy in young female rats.

\section{Acknowledgements}

This work was supported by grants from The National Council for Scientific and Technological Development (CNPq, Brazil) and by Espírito Santo Research Foundation (FAPES/FUNCITEC, ES, Brazil). We thank Dr Erinne Dabkowski for editorial assistance.

\section{Authors' contributions}

PAS was responsible for the large part of data acquisition and its analysis. RJRF, FAA, T GP contributed on the data acquisition, analysis and the discussion of results. VDV and SI dressed the experimental protocol, drafted the manuscript, discussion the data and results providing funding for the study. All authors read and approved the final version of the manuscript.

\section{Competing interests}

The authors declare that they have no competing interests.

Received: 3 January 2011 Accepted: 23 April 2011

Published: 23 April 2011

\section{References}

1. The ESHRE Capri Workshop Group: Hormones and cardiovascular health in women. Hum Reprod Update 2006, 12:483-497.

2. Mosca L, Manson JE, Sutherland SE, Langer RD, Manolio T, Barrett-Connor E: Cardiovascular disease in women: a statement for healthcare professionals from the American Heart Association. Circulation 1997, 96:2468-2482.

3. Mosca L, Banka CL, Benjamin EJ, Berra K, Bushnell C, Lolor RJ, Ganiats TG, et al: Evidence-based guidelines for cardiovascular disease prevention in women: 2007 update. JACC 2007, 49:1230-1250. 
4. Kuroski de Bold ML: Estrogen, natriuretic peptides and the reninangiotensin system. Cardiovasc Res 1999, 41:524-531.

5. Wenger NK, Speroff L, Packard B: Cardiovascular health and disease in women. N Engl J Med 1993, 22:247-256.

6. Hayward CS, Kalnis WV, Kelly RP: Acute effects of 17B- estradiol on ventricular and vascular hemodynamics in postmenopausal women. Am J Physiol 2000, 279:H2277- $\mathrm{H} 2284$.

7. Grady D, Herrington D, Bittner V, Blumenthal R, Davidson M, Hlatky M, Hsia J, Hulley S, Herd A, Khan S, Newby LK, Waters D, Vittinghoff E, Wenger N: HERS Research Group Cardiovascular disease outcomes during 6.8 years of hormone therapy: Heart and Estrogen/progestin Replacement Study follow-up (HERS II). JAMA 2002, 3:49-57.

8. Bush TL, Barrett-Connor E, Cowan LD, Criqui MH, Wallace RB, Suchindran CM, Tyroler Hayward CS, Kalnis WW, Kelly RP: Acute effects of 17B- estradiol on ventricular and vascular hemodynamics in postmenopausal women. Am J Physiol 2000, 279:H2277-H2284.

9. Guetta V, Cannon RO: Cardiovascular effects of estrogen and lipidlowering therapies in postmenopausal women. Circulation 1996 93:1928-1937.

10. Grohé C, Kahlert S, Löbbert K, Stimpel M, Karas RH, Vetter H, Neyses L: Cardiac myocytes and fibroblasts contain functional estrogen receptors. FEBS Letters 1997, 13:107-112.

11. Grohé C, Kahlert S, Löbbert K, Vetter H: Expression of oestrogen receptor alpha and beta in rat heart: role of local oestrogen synthesis. $J$ Endocrinol 1998, 156:R1-7.

12. Alecrin IN, Aldrighi JM, Caldas MA, Gebara OC, Lopes NH, Ramires JA: Acute and chronic effects of oestradiol on left ventricular diastolic function in hypertensive postmenopausal women with left ventricular diastolic dysfunction. Heart 2004, 90:777-781.

13. Schaible TF, Malhotra A, Ciambrone G, Scheuer J: The effects of gonadectomy on left ventricular function and cardiac contractile proteins in male and female rats. Circ Res 1984, 54:38-49.

14. Scheuer J, Malhotra A, Schaible TF, Capasso J: Effects of gonadectomy and hormonal replacement on rat hearts. Circ Res 1987, 61:12-19.

15. Ren J, Hintz KK, Roughead ZKF, Duan J, Colligan PB, Ren BH, Lee KJ Zeng $\mathrm{H}$ : Impact of estrogen replacement on ventricular myocyte contractile function and protein kinase B/Akt activation. Am J Physiol 2003, 284:H1800-H1807.

16. Bupha-Intr T, Wattanapermpool J: Regulatory role of ovarian sex hormones in calcium uptake activity of cardiac sarcoplasmic reticulum. Am J Physiol 2006, 291:H1101-H1108.

17. Chu SH, Goldspink P, Kowalski J, Beck J, Schwertz DW: Effect of estrogen on calcium-handling proteins, beta-adrenergic receptors, and function in rat heart. Life Sci 2006, 79:1257-1267.

18. Kravtsov GM, Kam KWL, Liu J, Wu Song, Wong TM: Altered $\mathrm{Ca}^{2+}$ handling by ryanodine receptor and $\mathrm{Na}^{+}-\mathrm{Ca}^{2+}$ Exchange in the heart from ovariectomized rats: role of protein kinase A. Am J Physiol 2007, 292:1625-1635

19. Simmerman HK, Jones LR: Phospholamban: Protein Structure, Mechanism of Action and Role in Cardiac Function. Physiol Rev 1998, 78:921-947.

20. Brittsan $A G$, Kranias $E G$ : Phospholamban and cardiac contractile function. J Mol Cell Cardiol 2000, 32:2131-2139.

21. Waynforth HB, Flecknell PA: Specific surgical operations. Experimental and Surgical Technique in the rat. Academic, San Diego, CA 1998, 276-278.

22. Bers DM, Perez-Reyes E: Ca channels in cardiac myocytes: structure and function in Ca influx and intracellular Ca release. Cardiovasc Res 1999, 42:339-60

23. Brodde OE, Michel MC: Adrenergic and muscarinic receptors in the human heart. Pharmacol Rev 1999, 51:651-690.

24. Sonnenblick EH: Determinants of active state in heart muscle: Force, velocity, instantaneous muscle length and time. Fed Proc 24(suppl):1396-1965

25. Koss KL, Kranias EG: Phospholamban: a prominent regulator of myocardial contractility. Circ Res 1996, 79:1059-1063.

26. Bocalini DS, Tucci PJ: Developed Force of Papillary Muscle What Index Correctly Indicates Contractile Capacity? Int Heart J 2009, 5:643-652.

27. Kadambi VJ, Ponniah S, Harrer J, Hoit B, Dorn GW, Walsh RA, Kranias EG: Cardiac-specific overexpression of phospholamban alters calcium kinetics and resultant cardiomyocyte mechanics in transgenic mice. $J$ Clin Invest 1996, 97:533-539.
28. Kiss E, Jakab G, Kranias EG, Edes I: Thyroid hormone-induced alterations in phospholamban protein expression. Regulatory effects on sarcoplasmic reticulum Ca2+ transport and myocardial relaxation. Circ Res 1994, 75:245-251.

29. Wattanapermpool J: Increase in calcium responsiveness of cardiac myofilament activation in ovariectomized rats. Life Sci 1998, 63:955-964.

30. Miller VM, Duckles SP: Vascular actions of estrogens: functional implications. Pharmacol Rev 2008, 60:210-241.

31. Bianchi PR, Gumz BP, Giuberti K, Stefanon I: Myocardial infarction increases reactivity to phenylephrine in isolated aortic rings of ovariectomized rats. Life Sci 2006, 78:875-881.

32. Mendelsohn ME, Karas RH: Molecular and cellular basis of cardiovascular gender differences. Science 2005, 308:1583-1587.

33. Thawornkaiwong A, Preawnim S, Wattanapermpool J: Upregulation of beta 1-adrenergic receptors in ovariectomized rat hearts. Life Scis 2003, 72:1813-1824.

34. Johnson BD, Zheng W, Korach KS, Scheuer T, Catterall WA, Rubanyi GM: Increased expression of the cardiac L-type calcium channel in estrogen receptor-deficient mice. J Gen Physiol 1997, 110:135-140.

35. Jiang C, Poole-Wilson PA, Sarrel PM, Mochizuki S, Collins P, MacLeod KT: Effect of 17 beta-oestradiol on contraction, $\mathrm{Ca} 2+$ current and intracellular free $\mathrm{Ca} 2+$ in guinea-pig isolated cardiac myocytes. $\mathrm{Br} J$ Pharmacol 1992, 106:739-745.

36. Kilic A, Javadov S, Karmazyn M: Estrogen exerts concentration-dependent pro-and anti-hyperthophic effects on adult cultured ventricular myocytes. Role of NHE-1 in estrogen-induced hyperthophy. J Mol Cell Cardiol 2009, 46:360-369.

37. Waggoner JR, Ginsburg KS, Mitton BA, Haghighi K, Robbins J, Bers DM, Kranias EG: Phospholamban overexpression in rabbit ventricular myocytes does not alter sarcoplasmic reticulum calcium transport. Am J Physiol 2009, 296:H698-703.

doi:10.1186/1477-7827-9-54

Cite this article as: Paigel et al:: Myocardial contractility is preserved early but reduced late after ovariectomy in young female rats. Reproductive Biology and Endocrinology 2011 9:54.

\section{Submit your next manuscript to BioMed Central and take full advantage of:}

- Convenient online submission

- Thorough peer review

- No space constraints or color figure charges

- Immediate publication on acceptance

- Inclusion in PubMed, CAS, Scopus and Google Scholar

- Research which is freely available for redistribution

Submit your manuscript at www.biomedcentral.com/submit
Ciomed Central 